\title{
Correction to: The role of travel demand and network centrality on the connectivity and resilience of an urban street system
}

\author{
Meisam Akbarzadeh ${ }^{1}$. Soroush Memarmontazerin ${ }^{1}$ - Sybil Derrible ${ }^{2,3}$. \\ Sayed Farzin Salehi Reihani ${ }^{1}$
}

Published online: 13 September 2019

(c) Springer Science+Business Media, LLC, part of Springer Nature 2019

\section{Correction to: Transportation (2019) 46:1127-1141 https://doi.org/10.1007/s11116-017-9814-y}

In the original publication of the article, the first, second and fourth authors' affiliations are published incorrectly. The correct affiliation is given in this correction.

Publisher's Note Springer Nature remains neutral with regard to jurisdictional claims in published maps and institutional affiliations.

The original article can be found online at https://doi.org/10.1007/s11116-017-9814-y.

Meisam Akbarzadeh

makbarzadeh@cc.iut.ac.ir

Sybil Derrible

derrible@uic.edu

Sayed Farzin Salehi Reihani

farzin.salehi@te.iut.ac.ir

1 Department of Transportation Engineering, Isfahan University of Technology, Isfahan, Iran

2 Complex and Sustainable Urban Networks (CSUN) Laboratory, University of Illinois at Chicago, Chicago, USA

3 Department of Civil and Materials Engineering, University of Illinois at Chicago, Chicago, USA 